\title{
Analyzing Students' Thinking Process in Solving Linear Algebra Problem
}

\author{
Arjudin Arjudin* \\ Mathematics Education Study Program \\ Universitas Mataram \\ Mataram, Indonesia \\ arjudin@unram.ac.id
}

\author{
Sri Subarinah \\ Mathematics Education Study Program \\ Universitas Mataram \\ Mataram, Indonesia
}

\author{
Rahadi Suryadi \\ Mathematics Education Study Program \\ Universitas Mataram \\ Mataram, Indonesia
}

\begin{abstract}
This explorative study aims at analyzing the students' thinking process in solving linear algebra related problems based on four levels of thinking which are Recall, Basic, Critical and Creative. To gain the data, the study was conducted in a state university in Mataram, Indonesia. The participants were 55 students from two classes in mathematics education study program who took linear algebra course. The data were gathered through written test in linear algebra. Then, it was followed by a reflective questionnaire. The gathered data were analyzed quantitatively dan qualitatively using descriptive method. The results showed that quantitatively, the students' problem-solving score was in low and intermediate category. Furthermore, in term of thinking process, the students were mostly thinking in basic and critical thinking levels. The findings are beneficial to support the improvement in teaching linear algebra to promote higher level thinking skill of the students especially in mathematics education study program.
\end{abstract}

Keywords - analysis, thinking process, linear algebra.

\section{INTRODUCTION}

Problem solving is an integrated skills in mathematics [1] \& [2] that should be learned by people in all ages. It is related to the activity of finding solution of a problem, making connection between concepts in mathematics. As it has primary function in human's basic needs, the attempt to develop problem solving ability is started early (see [3] $\&[4])$.

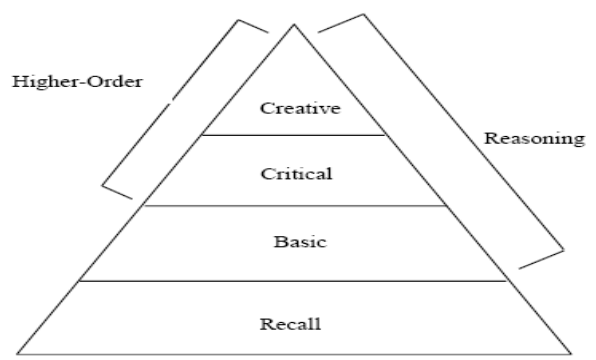

Fig. 1. Thinking Hierarchy

In general, there are four steps in problem solving including orientation, preparation, application and reflection [5]. To solve mathematical problem effectively, a student needs to have a good thinking process. According to Krulik \& Milou [6], there are four levels of thinking namely Recall, Basic, Critical and Creative. The level is hierarchical where the last two skills are considered as Higher-Order Thinking (Figure 1).

Higher-Order Thinking skills can be developed by a meaningful learning process. Here, teacher played a crucial role to setting a rich environment for students to gain optimum experience [7]. The mastery of Higher-Order Thinking brings benefits to students, in many aspects such as to broaden the range of mathematics topics and its application in daily life, emphasize the connection between mathematical ideas, solve problems and create representation for their ideas [8] \& [9].

Students' thinking process is one of the noticeable problems in linear algebra course of mathematics education study program throughout the years. The development of algebraic thinking plays an important role to enable students in learning linear algebra effectively. Nowadays, there are attempts to promote students' algebraic thinking in earlier age by implementing prealgebra course [10], [11] \& [12].

Linear algebra is an advance course in higher education. The mastery in learning linear algebra is highly influenced by how well the students were doing algebra during their school time, from elementary to high school [13]. Furthermore, it was found that the students mastered procedural fluency rather than conceptual understanding [14]. Usually, the students encountered difficulties when facing analytical problems since it required them to have higher order thinking skills such as creative and critical. From the observation, it was found that most of the students were only in recall and basic level thinking.

The previous study also found that the students have difficulties in establishing relationship among concepts in linear algebra, i.e. eigen and vector eigen values, also basis and dimension [15]. In other study, it was revealed that the students also cannot seeing the relation between algebraic procedures and the basic number characteristics [6].

Reflecting on the aforementioned conditions, this study aimed to investigate the students' thinking process in solving problems in linear algebra. By doing that, we will be able to classify the students' thinking process with its description, and further referred to in improving students problem solving skills. This study will be useful to give a recommendation for lecturers and students to determine the best learning route in linear algebra.

\section{METHODS}

To answer the research question, the present study employed explorative method. The participants were 55 students from two classeses in mathematics education study program who took linear algebra course in a state university in Mataram, Indonesia. 
Participants were assigned to the written test in linear algebra in which they need to provide their responses. The test was followed by fulfilling reflective questionnaire. The data were analyzed qualitatively and quantitatively using descriptive method.

The students' responses were categorized based on the level of problem-solving abilities, which were low, intermediate and high. After that, two participants in each category were further analyzed to gain information concerning their thinking processes, which can be distinguished into Recall, Basic, Critical and Creative. Therefore overall, six students' responses will be deeply analyzed. To confirm the result, students' responses in reflective questionnaire will be considered.

Each thinking level has ten characteristic indicators. The description of the indicators can be seen in Table 1 .

TABLE 1. INDICATORS OF THINKING LEVEL

\begin{tabular}{|c|c|}
\hline Code & Indicators \\
\hline \multicolumn{2}{|c|}{ RECALL THINKING } \\
\hline R1 & $\begin{array}{l}\text { Remembering the procedure of elimination and substitution to } \\
\text { solve linear equation system }\end{array}$ \\
\hline $\mathrm{R} 2$ & $\begin{array}{l}\text { Remembering the procedure of elementary row operation to } \\
\text { solve linear equation system }\end{array}$ \\
\hline R3 & $\begin{array}{l}\text { Remembering the procedure of cofactor expansion to calculate } \\
\text { determinant of matrix }\end{array}$ \\
\hline R4 & $\begin{array}{l}\text { Remembering the procedure of elementary row operation to } \\
\text { calculate determinant of matrix }\end{array}$ \\
\hline R5 & Remembering the procedure of adjoint to find inverse of matrix \\
\hline R6 & $\begin{array}{l}\text { Remembering the procedure of elementary row operation to } \\
\text { find inverse of matrix }\end{array}$ \\
\hline R7 & Remembering the axiom of vector spaces \\
\hline R8 & Remembering the requirement to be subspaces \\
\hline R9 & $\begin{array}{l}\text { Knowing the symbol and notation in the theorem that will be } \\
\text { proved }\end{array}$ \\
\hline R10 & $\begin{array}{l}\text { Knowing the meaning of sentence in the theorem that will be } \\
\text { proved }\end{array}$ \\
\hline \multicolumn{2}{|c|}{ BASIC THINKING } \\
\hline B1 & $\begin{array}{l}\text { Applying the procedure of elimination and substitution to solve } \\
\text { linear equation system }\end{array}$ \\
\hline B2 & $\begin{array}{l}\text { Applying the procedure of elementary row operation to solve } \\
\text { linear equation system }\end{array}$ \\
\hline B3 & $\begin{array}{l}\text { Applying the procedure of cofactor expansion to calculate } \\
\text { determinant of matrix }\end{array}$ \\
\hline B4 & $\begin{array}{l}\text { Applying the procedure of elementary row operation to } \\
\text { calculate determinant of matrix }\end{array}$ \\
\hline B5 & Applying the procedure of adjoint to find inverse of matrix \\
\hline B6 & $\begin{array}{l}\text { Applying the procedure of elementary row operation to find } \\
\text { inverse of matrix }\end{array}$ \\
\hline B7 & Giving the examples of set in a vector space \\
\hline B8 & Giving the operation defined in the example of a vector space \\
\hline B9 & Giving the examples of set in a subspace \\
\hline B10 & $\begin{array}{l}\text { Identifying the provided information and what will be proved in } \\
\text { a theorem }\end{array}$ \\
\hline \multicolumn{2}{|c|}{ CRITICAL THINKING } \\
\hline $\mathrm{C} 1$ & $\begin{array}{l}\text { Finding the solution of linear equation system by applying the } \\
\text { procedure of elimination and substitution }\end{array}$ \\
\hline $\mathrm{C} 2$ & $\begin{array}{l}\text { Finding the solution of linear equation system by applying the } \\
\text { procedure of elementary row operation }\end{array}$ \\
\hline $\mathrm{C} 3$ & $\begin{array}{l}\text { Finding the determinant of matrix using the procedure of } \\
\text { cofactor expansion }\end{array}$ \\
\hline $\mathrm{C} 4$ & $\begin{array}{l}\text { Finding the determinant of matrix using the procedure of } \\
\text { elementary row operation }\end{array}$ \\
\hline C5 & Finding the inverse of matrix using the procedure of adjoint \\
\hline C6 & $\begin{array}{l}\text { Finding the inverse of matrix using the procedure of elementary } \\
\text { row operation }\end{array}$ \\
\hline $\mathrm{C} 7$ & Giving the correct examples of set in a vector space \\
\hline $\mathrm{C} 8$ & Giving the correct operation defined in the example of a vector \\
\hline
\end{tabular}

\begin{tabular}{|l|l|}
\hline Code & Indicators \\
\hline C9 & space \\
\hline C10 & Fining the correct examples of set in a subspace \\
\hline CREATIVE THINKING \\
\hline V1 & $\begin{array}{l}\text { Finding the correct solution of linear equation system by } \\
\text { applying the procedure of elimination and substitution }\end{array}$ \\
\hline V2 & $\begin{array}{l}\text { Finding the correct solution of linear equation system by } \\
\text { applying the procedure of elementary row operation }\end{array}$ \\
\hline V3 & $\begin{array}{l}\text { Finding the correct determinant of matrix using the procedure of } \\
\text { cofactor expansion }\end{array}$ \\
\hline V4 & $\begin{array}{l}\text { Finding the correct determinant of matrix using the procedure of } \\
\text { elementary row operation }\end{array}$ \\
\hline V5 & $\begin{array}{l}\text { Finding the correct inverse of matrix using the procedure of } \\
\text { adjoint }\end{array}$ \\
\hline V6 & $\begin{array}{l}\text { Finding the correct inverse of matrix using the procedure of } \\
\text { elementary row operation }\end{array}$ \\
\hline V7 & $\begin{array}{l}\text { Giving the correct examples of set in a vector space completed } \\
\text { with the reasons }\end{array}$ \\
\hline V8 & $\begin{array}{l}\text { Giving the correct operation defined in the example of a vector } \\
\text { space completed with the reasons }\end{array}$ \\
\hline V9 & Applying the idea to proof a theorem \\
\hline V10 & Formulating a conclusion from the proof of the theorem \\
\hline
\end{tabular}

The participant is classified in certain level thinking if $70 \%$ or more of the indicators are fulfilled.

\section{RESULTS AND DISCUSSION}

After the participants solved the written test, we analyzed the result by grouping the students' scores into low, intermediate and high. The percentages of the students in each group were $43.6 \%, 49.1 \%$, and $7.3 \%$ respectively. Two students from each category were selected to further analysis. The students with high scores were coded as S-01 and S-02, intermediate were coded as S-03 and S-04 and low were coded as S-05 and S-06. The following discussion qualitatively analyzes each of the students' thinking process.

\section{A. S-01Thinking Process Analysis}

S-01 was able to solve the system of linear equation problem by employing Elementary Row Operation (ERO), but not other methods. S-01 attempted to apply Cramer Rule to solve the given problem. However, it cannot be done since the determinant of the matrix that represent the linear equation system was equal to zero. Also, in the reflection questionnaire, $\mathrm{S}-01$ acknowledged the possibility of using elimination or substitution method. Nevertheless, during the process it was found that the process leads to inconsistent result. Then, S-01 terminated it.

When solving the problem related to determinant, S01 was able to implement two methods, cofactor expansion and ERO. S-01 was also success in finding the inverse of matrix by using two methods, adjoint and ERO. Furthermore, S-01 could provide the correct examples of vector space and subspace. S-01 was reported to perform poorly in the last problem which was about the proof of theorem.

From the level of thinking (see Table 1), S-01 fulfilled all criteria for Recall, 8 out of 10 criteria for Basic (except B2 and B10), 8 out of 10 for Critical (except for $\mathrm{C} 2$ and $\mathrm{C} 10$ ) and 7 out of 10 for Creative (except V2, V9 and V10). Therefore, it can be concluded that S-01 was in Creative thinking level. 


\section{B. S-02 Thinking Process Analysis}

In solving the first problem related to linear equation system, S-02 used ERO and Elimination/Substitution. The difficulty encountered in the next problem related to find the determinant using ERO (cofactor expansion was correctly applied here). As can be seen in Fig. 2, S-02 employed an operation which is not a part of ERO.

\begin{tabular}{|c|c|c|c|c|c|c|c|c|}
\hline-2 & 0 & -16 & 0 & & -6 & 0 & 0 & 0 \\
\hline 3 & 2 & 0 & 11 & & 3 & 2 & 0 & 11 \\
\hline 0 & 0 & -3 & 3 & & 0 & 0 & -3 & 3 \\
\hline 5 & -2 & 0 & 2 & & 5 & -2 & 0 & 2 \\
\hline
\end{tabular}

Fig. 2. S-02 Error in ERO procedure

S-02 was also able to find the inverse of matrix by using adjoint method. Another strategy using ERO was also performed, however there was incorrect counting result in the process. Furthermore, S-02 successfully gave examples of vector space and subspace. S-02 was also able to work with the symbol and notation in the last problem. However, S-02 did not understand the requirement of the problem.

All in all, S-02 fulfilled all indicators in Recall, all indicators in Basic except B4 and B10, all indicators in Critical except $\mathrm{C} 4$ and $\mathrm{C} 10$, and 7 out of 10 indicators in Creative (all indicators excluding V4, V9 and V10). Therefore, S-02 can be categorized to have thinking process in Creative level.

\section{S-03 Thinking Process Analysis}

S-03 was able to carry out elimination/substitution procedures to solve the system of linear equation problem. However, the result was wrong since there is an incorrect step in the process (see Fig.3). On the, the final solutions were not written. S-03'a answer using ERO stopped in the conclusion that the system will have infinite solutions.

\begin{aligned} $7 y-m z & =10 \\ 7 y-14 z & =10 \\$\hline $0-0 & =0 \\$ subtitusi o ke per $(1)(2)(3) & -4 \\ x+2(0)-3(z) & =4 \\ 3 x-(0)+5(0) & =2 \\ x & =2 / 3\end{aligned}$

Fig. 3. S-03 Error in Elimination/Substitution Method

The determinant related problem was correctly solved by using cofactor expansion. Nevertheless, S-03 was not able to find determinant by using ERO. Similar finding happened in the next problem to find the invers of matrix, where S-03 was able to use adjoin method but not with the ERO method. Furthermore, S-03 was able to give examples of vector space and sub space. S-03 also constructed idea to proof the theorem given in the last problem, but was not done in executing the steps due to time limitation.

Based on the level of thinking, S-03 mastered all criteria for Recall, 7 out of 10 criteria for Basic (all criteria except B2, B4 and B6), 6 out of 10 for Critical (all criteia except $\mathrm{C} 1, \mathrm{C} 2, \mathrm{C} 4$ and C6) and 4 out of 10 for Creative (which were V3, V5, V7 and V8). Therefore, it can be concluded that S-01 was in Critical thinking level.

\section{S-04 Thinking Process Analysis}

S-04 was able to solve the first problem related to linear equation system by using ERO. The procedure, result and conclusion were correct; but the general form of the solutions was not provided. S-04 also correctly answered the determinant of matrix by using cofactor expansion and ERO. Minor error found in ERO in which the subject incorrectly wrote the notation for determinant.

Furthermore, S-4 answered the inverse of matrix by using adjoint and ERO methods. However, the steps of employing adjoint method was not given. In ERO, there was a mistake in writing the notation for matrices in which (A I I) were symbolized as AI which actually represents the multiplication of two matrices.

In vector space and subspaces, $\mathrm{S}-04$ was able to give the correct examples, but not completed by the operation. There was also a symbol ambiguity in writing the notation of the set and the vector as the element of the set. For the last problem related to theorem proof, $\mathrm{S}-04$ successfully described the steps of proving, but it was conceptually incorrect.

Based on the level of thinking, S-04 achieved 7 out of 10 criteria for Recall (all criteria except R2, R4 and R6), 7 out of 10 criteria for Basic (all criteria except B1, B8 and B10), 7 out of 10 for Critical (all criteria except C1, C8 and $\mathrm{C} 10$ ) and only 3 out of 10 for Creative (which were V2, V3 and V7). Therefore, it can be concluded that S-01 was in Critical thinking level.

\section{E. S-05 Thinking Process Analysis}

Similar with the errors showed by S-03 work, S-05 also incorrectly chose the value for the solution of linear equation system through the elimination/substitution procedure. When applying ERO, S-05 did structural error in the operation (see Fig. 4).

$\frac{\left[\begin{array}{cccc}1 & 2 & -3 & 4 \\ 0 & -7 & 14 & -10 \\ 0 & 0 & 0 & 0\end{array}\right]+B_{2}+4 B_{1}\left[\begin{array}{cccc}1 & 2 & -3 & 4 \\ 4 & 1 & 2 & 6 \\ 0 & 0 & 0 & 0\end{array}\right]}{\text { Fig 4 S-05 Error in ERO procedure }}$

In addition, S-05 was able to determine the determinant of matrix by employing cofactor expansion method, but not by ERO. However in finding the inverse of matrix, ERO method was correctly applied. S-05 also tried to solve the inverse by using adjoint method, but a mistake occured in which the sign was incorrectly assigned in the position of negative permutation. This happened since S-05 applied cofactors of matrix directly from minor matrix without looking at the positive or negative signs. For the rest problems related to vector space, subspaces and theorem proof; S-05 was reported unable to provide correct answers.

From the level of thinking, S-05 fulfilled 7 out of 10 in Recall (all critera except for R7, R8 and R9), 5 out of 10 criteria for Basic (which were B1, B2, B3, B4 and B5), 4 out of 10 for Critical (which were C2, C3, C5 and C6) and 2 out of 10 for Creative (which were V3 and V6). Therefore, it can be concluded that S-01 was in Basic thinking level. 


\section{F. S-06 Thinking Process Analysis}

S-06 was not able to find the solution of the linear equation system by using elimination/substitution nor ERO method. ERO was also failed to be employed when S-06 attempted to find the determinant and the inverse of matrix. The determinant was correctly determined by employing cofactor expansion method while inverse was found by using cofactor expansion. However, S-06 did not write the adjoint process in detail, and the result was not presented in its simplest form.

Related to vector space and subspaces, even though S-06 was able to provide the examples, they were not completed by the appropriate operation in the space. Also, S-06 notations writing was not consistent that leads to some ambiguities. For the last problem, S-06 provided no responses.

From the level of thinking, S-06 fulfilled 7 out of 10 in Recall (all criteria except for R2, R4 and R6), 5 out of 10 criteria for Basic (which were B1, B2, B4, B5 and B6), 3 out of 10 for Critical (which were C3, C7 and C10) and only 1 out of 10 for Creative (which was V4). Therefore, it can be concluded that S-01 was in Basic thinking level.

From the above results, it can be observed that the participants with higher scores tend to have Creative thinking level, while the one with intermediate scores tend to have Critical thinking level. Accordingly, the participants with low score usually in Basic thinking level. By considering the percentages of students in each category, we can infer that the subjects of the study were majorly assigned in Basic to Critical thinking levels. The result is in line with the study of Jacob [16] who reported a linear relation between critical thinking and mathematics achievement of the students. Furthermore, there is also the correlation between students' higher order thinking skills with the problem posing ability [17].

Considering overall findings of the study, it is necessary for the lecturers to provide meaningful guidance for the students. One recommendation is by using problem based learning during the learning process [18] in which the lecturer provides scaffolding to enhance students' mastery in learning concepts [19].

\section{CONCLUSION}

From the analysis of the study, it can be concluded that the students' ability in solving linear algebra related problems are mostly in low and intermediate category. Also, the students' thinking process in solving linear algebra are in basic to critical levels. These results lead us to recommend students to learn deeper in the content and train the mastery in solving problem to perform better in the linear algebra course. To support the optimum result, the lecturers should consider the students thinking characteristics and their relation towards the learning content. Through that efforts, the errors during learning can be minimized.

\section{REFERENCES}

[1] Socas M and J. Hernandez, "Mathematical Problem Solving in Training Elementary Teachers from a Semiotic Logical Approach," Math. Enthus., vol. 10, no. 1-2, pp. 191-218, 2013, doi:
$10.1177 / 135485650300900208$.

[2] M. Guzman Gurat, "Mathematical problem-solving strategies among student teachers," J. Effic. Responsib. Educ. Sci., vol. 11, no. 3, pp. 53-64, 2018, doi: 10.7160/eriesj.2018.110302.

[3] D. A. Perihan, "Preschool childrens skills in solving mathematical word problems," Educ. Res. Rev., vol. 10, no. 18, pp. 2539-2549, 2015, doi: 10.5897/err2015.2431.

[4] H. Palmér and J. van Bommel, "Problem Solving in Early Mathematics Teaching-A Way to Promote Creativity?," Creat. Educ., vol. 09, no. 12, pp. 1775-1793, 2018, doi: 10.4236/ce.2018.912129.

[5] M. P. Carlson and I. Bloom, "The Cyclic Nature of Problem Solving: An Emergent Multidimensional Problem-Solving Framework," Educ. Stud. Math., vol. 58, no. 1, pp. 45-75, 2005, doi: 10.1007/s10649-005-0808-x.

[6] S. Krulik and R. Milou, Teaching Mathematics in Middle School, A Practical Guide, vol. 20, no. 9. Boston: Pearson Education Inc, 2003.

[7] D. Sukla and A. P. Dungsungneon, "Students Perceived Level and Teachers Teaching Strategies of Higher Order Thinking Skills; A Study on Higher Educational Institutions in Thailand," J. Educ. Pr., vol. 7, no. 12, pp. 211-219, 2016.

[8] M. Knapp et al., Teaching for Meaning in High-Poverty Classrooms. New York: Teachers College Press, 1989.

[9] G. S. Pratama and H. Retnawati, "Urgency of Higher Order Thinking Skills (HOTS) Content Analysis in Mathematics Textbook," J. Phys. Conf. Ser., vol. 1097, no. 1, 2018, doi: 10.1088/1742-6596/1097/1/012147.

[10]R. A. Apsari, R. I. I. Putri, Sariyasa, M. Abels, and S. Prayitno, "Geometry representation to develop algebraic thinking: A recommendation for a pattern investigation in pre-algebra class," $J$. Math. Educ., vol. 11, no. 1, pp. 45-58, 2020, doi: 10.22342/jme.11.1.9535.45-58.

[11]R.A Apsari., Sariyasa, S., Putri, R.I.I., Gunawan, G; Prayitno, S. "Understanding Students' Transition from Arithmetic to Algebraic Thinking in the Pre-Algebraic Lesson Understanding Students , Transition from Arithmetic to Algebraic Thinking in the PreAlgebraic Lesson," J. Phys. Conf. Ser., vol. 1471, pp. 1-7, 2020, doi: 10.1088/1742-6596/1471/1/012056.

[12]R. A. Apsari and F. H. J. Van Galen, "Patterns Investigation as a Pre-Algebraic Activity," in The 1st International Conference on Innovative Research Across Disciplines, 2015, pp. 36-39.

[13]N. Finkelstein, A. Fong, J. Tiffany-Morales, P. Shields, and M. Huang, College bound in middle school and high school? How math course sequences matter. Sacramento, CA: The Center for the Future of Teaching and Learning at WestEd, 2012.

[14] A. Jupri and R. Sispiyati, "Students' algebraic proficiency from the perspective of symbol sense," Indones. J. Sci. Technol., vol. 5, no. 1, pp. 86-94, 2020, doi: 10.17509/ijost.v5i1.23102.

[15]D. A. Lapp, M. A. Nyman, and J. S. Berry, "Student connections of linear algebra concepts: an analysis of concept maps," Int. J. Math. Educ. Sci. Technol., vol. 41, no. 1, pp. 1-18, 2010, doi: 10.1080/00207390903236665.

[16] S. M. Jacob, "Mathematical achievement and critical thinking skills in asynchronous discussion forums," Procedia - Soc. Behav. Sci., vol. 31, no. 2011, pp. 800-804, 2012, doi: 10.1016/j.sbspro.2011.12.144.

[17]N. Ngah, Z. Ismail, Z. Tasir, and M. N. H. M. Said, "Students' higher order thinking skills and their relationships with problem posing ability," Adv. Sci. Lett., vol. 23, no. 4, pp. 2876-2879, 2017, doi: 10.1166/asl.2017.7589.

[18] Mulyono and R. Hadiyanti, "Analysis of mathematical problemsolving ability based on metacognition on problem-based learning," J. Phys. Conf. Ser., vol. 983, no. 1, 2018, doi: 10.1088/17426596/983/1/012157.

[19]I. N. Gita and R. A. Apsari, "Scaffolding in problem based learning to increase students' achievements in linear algebra," J. Phys. Conf. Ser., vol. 1040, no. 1, 2018, doi: 10.1088/1742-6596/1040/1/012024. 